\title{
Presentación: ¿Qué fue de la contracultura? Miradas teóricas desde las lógicas de la comunicación y el espectáculo
}

What has happened to counterculture? Theoritical insights from the logic of communication and spectacle

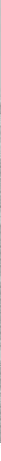

IC Journal (https://ic-journal.org/) revista indexada en SCOPUS y Thomsom Reuters $\mathrm{ESCl}$, de acceso abierto, propone a la comunidad investigadora concitar miradas acerca de la historia, bases ideológicas e influencia de la contracultura en las conflictivas dinámicas sociales que vivimos. Un campo de estudio que a menudo queda fuera de los intereses académicos contemporáneos y que, sin embargo, no conviene olvidar, no solo porque las bases de agitación y los nuevos imaginarios contraculturales que emergieron a finales de la década de 1950 y que tuvieron su apogeo desde mediados de la década de 1960 hasta finales de la de 1970, dejaron un poso de habitus socioculturales, líneas de pensamiento político y estilemas artísticos que aún perduran e incluso subyacen, muchas veces sin ser notados, en las lógica culturales contemporáneas, sino también, porque su hibridación con tendencias del pensamiento crítico de finales del siglo XX (las que derivan principalmente de los planteamientos de Foucault, Deleuze y Guattari), su hondo calado en las corrientes de la cultura de masas fuera del mainstream (en las formas alternativas de las músicas pop, rock y hip-hop, en el cómic, en el cine independiente e incluso en series audiovisuales de éxito masivo como Breaking Bad o The Boys), su fermento en determinados ámbitos sociopolíticos y culturales como el feminismo, la Queer Theory o 
el ecologismo, entre otros, no ha sido suficientemente tenida en cuenta ni desde una perspectiva histórica ni tampoco desde el estudio teórico de los elementos que estructuran el imaginario contracultural en los discursos y prácticas de subversión respecto a los valores, comportamientos y principios del discurso de autoridad hegemónico.

Desde aproximadamente 1965 hasta finales de la década de 1970, pareció que la revolución cultural que había nacido alrededor del rock y la generación hippy podría conseguir provocar los cambios sociales que vaticinaban. La contracultura o cultura underground fue un conglomerado (pocas veces más que una propuesta de cambios en las costumbres y en las ideas sociales) de diversas corrientes de pensamiento crítico, surgidas fundamental, aunque no exclusivamente, entre la juventud norteamericana y europea, mayoritariamente blanca y universitaria: Ios movimientos por los derechos civiles, la New Left, las revisiones del marxismo en la vía abierta por Herbert Marcuse (1955 y 1964), el eco de las revueltas del mayo francés de 1968, la revolución espiritual de la cultura psicodélica que nació alrededor del LSD y la búsqueda de la libertad antisistema que habían propagado los escritores beatniks en la década de los 50, las relecturas pop de las filosofías místicas orientales y la música rock como principal vehículo de comunicacional cultural. Por primera vez en la historia de occidente pudo hablarse de la emergencia de una "cultura juvenil", que primero representó las ansias de identidad y las frustraciones de los teenagers norteamericanos y luego fue mutando hacia dominar los estándares de producción y consumo de la cultura de masas y, al mismo tiempo, generar discursos de subversión y transformación social del orden establecido.

Estas dos líneas culturales, denominadas habitualmente en los primeros años setenta del pasado siglo como mainstream y underground, respectivamente, se mantienen en la lógica cultural contemporánea, hasta el punto de que podría hablarse de una archicultura pop (Fernández Serrato, 2005), como línea maestra que articula los dispositivos sociosemióticos de la industria cultural en la postmodernidad.

Los tres números siguientes que propondrá a la comunidad científica IC, Revista Científica de Información y Comunicación, se centrarán ahondar en esta genealogía sociocultural de nuestro presente a través de monográficos dedicados al tema y publicados en la sección SELECTA de nuestra revista. En esta misma sección publicamos hoy, como adelanto, tres contribuciones al examen crítico de la contracultura. El primero es un estudio sobre la obra fotográfica de Alberto García-Alix, conocido (a su pesar) como el fotógrafo de la Movida madrileña de los años ochenta, que, bajo el título “Fotografía y contracultura en Estados Unidos y España: orígenes e institucionalización. Particularidades en la obra de Alberto García-Alix" nos ofrece el investigador de la 
Universidad de Sevilla Manuel Blanco Pérez. Le sigue un análisis del flamenco como forma cultural, a partir de la obra documental de Carles Bosch, del investigador ecuatoriano Miguel Alfonso Bouhaben: “Nomadismo, heterodoxia y subalterniadad del flamenco como forma de comunicación cultural. Análisis del documental Petitet (Carles Bosch, 2018)”. Finalmente, cierra este número de SELECTA una reflexión teórica sobre la “Genealogía de la cultura de masas. Crítica de la información como dominio: El caso del deporte como espectáculo" del investigador y Catedrático de Teoría de la Comunicación de la Universidad de Sevilla, Francisco Sierra Caballero, que analiza críticamente los principios económico-políticos que gobiernan las lógicas culturales del deporte como espectáculo de masas, donde se reflejan las estrategias de manipulación y control que ha puesto en práctica occidente a través de las manifestaciones contemporáneas de lo que podríamos denominar "la cultura del juego".

Adelantamos aquí la propuesta de IC Journal para el siguiente monográfico de SELECTA. Se organizará en torno a la necesidad de pensar más específicamente la dimensión histórica y genética de los discursos y políticas de crítica y liberación social que nacieron del underground y fundamentaron lo que luego se llamaría contracultura. Resulta paradójico el hecho de que muchos de estos discursos de subversión o simplemente marginales, acabaron entrando en el núcleo mismo del negocio de la cultura de masas en décadas posteriores, perdiendo todo su potencial de rebeldía, crítica y empuje de transformación social (el rock'n'roll, por supuesto, pero también el orientalismo, el misticismo, la cultura de la droga, el individualismo -una vez perdido su primitivo carácter anarcoide-, las subculturas juveniles...). El conocimiento de la naturaleza, los condicionantes, la cristalización de los discursos, géneros y retóricas contraculturales, así como sus efectos sociales y en la construcción de la "cultura-mundo" de la globalización, serán el objetivo de conocimiento que IC propone a la comunidad académica.

Los temas que se proponen para el próximo monográfico serán:

Discursos de la contracultura: Como toda producción simbólica, la contracultura produjo una serie de discursos propios (rock and roll) y alteró otros ya existentes (cómic, cine, escritura periodística, artes plásticas...) por medio de los cuales difundió su modo de entender la crítica de las costumbres y la subversión contra los principios ideológicos dominantes. Se propone en este apartado la realización de estudios sobre las características, retóricas y operaciones discursivas de 
transformación que se llevaron a cabo en la generación de productos simbólicos por parte de la contracultura.

Imaginarios contraculturales: ¿Cuáles fueron los flujos de los sentidos culturales que conformaron la emergencia de la contracultura? ¿Cuáles sus bases filosóficas y/o ideológicas? ¿Fue la contracultura una "excrecencia” no deseada de las lógicas simbólicas de la cultura de masas? ¿Llegó a construir la contracultura un sistema más o menos estructurado de principios, valores y sentidos sociales?

Políticas de la contracultura: El activismo político anti-stablishment estuvo en el origen de la agitación social de los movimientos contraculturales, ¿cuáles fueron sus nexos con las ideologías y los modos de organización política de colectividades y organizaciones que lo tomaron como bandera? ¿Hubo una coincidencia natural entre las políticas radicales y las producciones simbólicas de la contracultura o se aprovecharon los discursos del underground como vehículos de propaganda?

\section{Bibliografía}

Barbour, F. B. (Ed.) (1969). La revuelta del poder negro. Barcelona, Anagrama, 1993.

Braunstein, P. Y Doyle, M. (2002). Imagine Nation: The American Counterculture of the 1960's and 70's. New York, Routledge.

Carson, D. (2005). Grit, Noise and Revolution.Ann Arbor, University of Michigan Press.

Cohn, N. (1968). Awopbopaloobop Alopbamboom: Una historia de la música pop. Barcelona, Punto de Lectura, 2004.

Constantine, A. (2000). The Covert War Against Rock. New York, Feral House.

Costa, J. (2018). Cómo acabar de una vez por todas con la contracultura: Una historia subterránea de España.Madrid, Taurus

Danky, J.; Y Kitchen, D. (2009). Underground Classics: The Transformation of Comics into Comix. New York, Abrams. 
De Curtis, A. (1992a) (Ed.). Present Tense: Rock \& Roll and Culture. Durham, Duke University Press.

Esten, M. (1974). A Histoiry of Underground Comics. London, Ronin.

Fairfield, R. (2010). The Modern Utopian: Alternatives Communities of the 60's and 70's. Washington, Process.

Fernández Serrato, J.C. (2005). “Archicultura pop y comunicación intercultural”, IC, Revista Científica de Información y Comunicación, 2, pp. 79-102.

Feuer, L.S. (1969). The Conflict of Generations: The Character and Significance of Students Movement. New York, Basic Books.

Frith, S. (1978). Sociología del rock. Madrid, Júcar, 1980.

Frith, S.; Straw, W. Y Street, J. (eds.) (2001). La otra historia del rock. Barcelona, Robinbook, 2006.

Gaillard, A. (2009). Los Diggers: Revolución y contracultura en San Francisco (1966-1968).Logroño, Pepitas de Calabaza, 2010.

García Lloret, J. (2006). Psicodelia, hippies y underground en España.Zaragoza, Zona de Obras.

Goldstein, R. (1989). Reporting the Counterculture. London, Unwin Hyman.

Gonzalo, J. (2009-2014). Poder freak, Bilbao, Libros crudos. 3 vols.

Hebdige, D. (1987). Subculture: The Meanning of Style. London \& New York, Routledge.

Hoffman, A. (1969). Woodstock Nation. New York, Vintage Books.

Home, S. (1988). El asalto a la cultura: Corrientes utópicas desde el Letrismo a Class War. Barcelona, Virus, 2002.

Leary, Th. (1973). Confesiones de un adicto a la esperanza. Barcelona, Star Books, 1978. 
Lee, M. y Schlain, B. (1985). Acid Dreams: The Complete Social History of LSD: The $\mathrm{CIA}$, the Sixties an Beyond. New York, Groove Press.

Maffi, M. (1972). La cultura underground. Barcelona, Anagrama, 1975. 2 vols.

Marcus, G. (1975). Mystery Train: Imágenes de América en la música Rock \& Roll. Barcelona, Contra, 2013.

--- (1989). Rastros de carmín: Una historia secreta del siglo XX. Barcelona, Anagrama, 1993.

Marcuse, H. (1955). Eros y civilización. Barcelona, Ariel, 1981

--- (1964). El hombre unidimensional. Ensayo sobre la ideología de la sociedad industrial avanzada. Barcelona, Ariel, 1968.

McMillian, J. (2011). Smoking Typewriters: The Sixties Underground Press and the Rise of Alternative Media in America. Oxford, Oxford University Press.

McNally, D.(1979). Jack Kerouac: América y la Generación Beat. Barcelona, Paidós, 1992.

Méndez Rubio, A. (1997). Encrucijadas: elementos para una crítica de la cultura. Madrid, Cátedra.

--- (2016). Comunicación musical y cultura popular: Una introducción crítica. Valencia, Tirant lo Blanc.

Miles, B. (2004). Hippie. New York, Sterling.

Pardo, J.I. (2007). Esto no es música: Introducción al malestar en la cultura de masas. Barcelona, Galaxia Gutemberg/Círculo de lectores.

Peck, A. (1985). Uncovering the Sixties: The Life and Times of Underground Press. New York, Pantheon Books. 
Racionero, L. (1977). Filosofías del underground. Barcelona, Anagrama.

Roszak, T. (1970). El nacimiento de una contracultura. Barcelona, Kairós, 1978.

Seca, J.-M. (2001). Los músicos underground. Barcelona, Paidós, 2004.

Sinclair, J. (1972). Guitar Army. New York, Douglas Books.

Street, J. (1997). Política y cultura popular. Madrid, Alianza, 2000.

Talens, J. y Puig, L. (1993). Rocking, Writing and Arithmetic. Valencia, Eutopías.

--- (1999) (eds.). Las culturas del rock. Valencia, Pre-textos.

VV. AA. (2009: Motherfuckers! De los veranos del amor al amor armado. Madrid, La Felguera.

Wolfe, T. (1968a). La banda de la casa de la bomba y otras crónicas de la era pop. Barcelona, Anagrama, 2013.

--- (1968). Ponche de ácido lisérgico. Barcelona, Anagrama, 2017.

(1970). La izquierda exquisita \& Mau-mauando al parachoques. Barcelona, Anagrama, 2011. 